\title{
BMJ Open Are interventions for low-income groups effective in changing healthy eating, physical activity and smoking behaviours? A systematic review and meta-analysis
}

\author{
Eleanor R Bull, ${ }^{1}$ Stephan U Dombrowski, ${ }^{2}$ Nicola McCleary, ${ }^{3}$ Marie Johnston ${ }^{3}$
}

To cite: Bull ER, Dombrowski SU, McCleary N, et al. Are interventions for low-income groups effective in changing healthy eating, physical activity and smoking behaviours? A systematic review and meta-analysis. BMJ Open 2014;4:e006046. doi:10.1136/bmjopen-2014006046

- Prepublication history and additional material is available. To view please visit the journal (http://dx.doi.org/ 10.1136/bmjopen-2014006046).

Received 8 July 2014 Revised 15 October 2014 Accepted 6 November 2014

\section{CrossMark}

${ }^{1}$ NHS Grampian Public Health Directorate, Aberdeen, UK ${ }^{2}$ Division of Psychology, School of Natural Sciences, University of Stirling, Stirling, UK

${ }^{3}$ Aberdeen Health Psychology Group, Institute of Applied Health Sciences, College of Life Sciences and Medicine, University of Aberdeen, Aberdeen, UK

Correspondence to Eleanor R Bull; eleanor.bull@nhs.net

\section{ABSTRACT}

Objective: To conduct a systematic review and meta-analysis examining the effectiveness of behavioural interventions targeting diet, physical activity or smoking in low-income adults.

Design: Systematic review with random effects meta-analyses. Studies before 2006 were identified from a previously published systematic review (searching 1995-2006) with similar but broader inclusion criteria (including non-randomised controlled trials (RCTs)). Studies from 2006 to 2014 were identified from eight electronic databases using a similar search strategy. Data sources: MEDLINE, EMBASE, PsycINFO, ASSIA, CINAHL, Cochrane Controlled Trials, Cochrane Systematic Review and DARE.

Eligibility criteria for selecting studies: RCTs and cluster RCTs published from 1995 to 2014; interventions targeting dietary, physical activity and smoking; low-income adults; reporting of behavioural outcomes.

Main outcome measures: Dietary, physical activity and smoking cessation behaviours.

Results: 35 studies containing 45 interventions with 17000 participants met inclusion criteria. At postintervention, effects were positive but small for diet (standardised mean difference (SMD) $0.22,95 \% \mathrm{Cl} 0.14$ to 0.29 ), physical activity (SMD $0.21,95 \% \mathrm{Cl} 0.06$ to 0.36 ) and smoking (relative risk (RR) of $1.59,95 \% \mathrm{Cl}$ 1.34 to 1.89 ). Studies reporting follow-up results suggested that effects were maintained over time for diet (SMD $0.16,95 \% \mathrm{Cl} 0.08$ to 0.25 ) but not physical activity (SMD $0.17,95 \% \mathrm{Cl}-0.02$ to 0.37 ) or smoking (RR 1.11, $95 \% \mathrm{Cl} 0.93$ to 1.34 ).

Conclusions: Behaviour change interventions for lowincome groups had small positive effects on healthy eating, physical activity and smoking. Further work is needed to improve the effectiveness of behaviour change interventions for deprived populations.

\section{INTRODUCTION}

Health outcomes are strongly correlated with social position in societies across the western world: individuals from deprived backgrounds

\section{Strengths and limitations of this study}

- This was a comprehensive systematic review with meta-analysis to examine the effects of behavioural interventions in a deprived proportion of the population, namely those with a low income.

- We updated a previous review on this topic and focused exclusively on evidence from randomised controlled trials, which are often termed 'the gold standard' of research.

- Applying meta-analysis enabled us to summarise the data quantitatively and estimate pooled effect sizes, which could be compared to those for interventions from other population groups.

- We searched for studies where participants were described as 'low income' as this is a financially and socially relevant indicator of deprivation, but relevant papers not using this term may have been missed.

- The majority of the studies were conducted in the USA, potentially limiting generalisability and did not tend to describe their intervention content comprehensively, making it difficult to further explore 'what works' for people with a low income.

die younger and experience a greater proportion of their lives with a disability. ${ }^{1-5}$ In the most deprived areas of England, for example, life expectancy is approximately 8 years less, and disability-free life expectancy 15 years less than in the least deprived areas. ${ }^{1}$ Among several deprivation indicators, a person's individual or household income is widely recognised as being strongly positively correlated with health outcomes. ${ }^{3}$ The social gradient in health is predicted to steepen further ${ }^{2}$ despite policy efforts aimed at maximising equality. ${ }^{3-5}$

Behaviours linked to health, particularly healthy eating, physical activity and smoking, show a similar social gradient to health outcomes. Consumption of tobacco, a poor diet and a lack of physical activity are major risks 
to premature morbidity and mortality. ${ }^{6} 7$ People of lower socioeconomic status are more likely to smoke, ${ }^{5}$ be sedentary $^{8}$ and eat a poor $\operatorname{diet}^{9}$ compared with those of higher socioeconomic status. These behaviours have been suggested as mediators of the link between social position and health outcomes. ${ }^{10-12}$

\section{Changing health behaviours}

Given the potential improvements that changes in behaviour can bring to health, health research and clinical practice devotes considerable time and effort to behavioural interventions. For instance, stopping smoking increases life expectancy at any age and halves the risk of cardiovascular disease within 1 year. ${ }^{13}$ Experts agree that major improvements in public health will be brought about through behaviour changes in the population. 71415 Targeting behaviour change efforts at people at the lower end of the income spectrum is seen as a major means to reducing health inequalities. Gruer et al (ref ${ }^{12}, \mathrm{p} .5$ ) for instance argued that "the scope for reducing health inequalities related to social position [...] is limited unless many smokers in lower social positions can be enabled to stop smoking."

\section{Health behaviour change in low-income populations}

Existing behaviour change support for those disadvantaged by income may not be fit for purpose. ${ }^{14}$ Evidence suggests that people from low-income groups are more difficult to identify and successfully recruit to general population interventions. ${ }^{16-18}$ Moreover, it has been suggested that low-income populations may achieve poorer behaviour change outcomes following interventions compared with more affluent participants, resulting in poorer health outcomes ${ }^{19-21}$ and potentially leading to intervention-generated inequalities. ${ }^{22}$

In studies targeted at the whole population rather than specific subgroups, Michie et $a l^{23}$ have argued that observed differences in outcomes between socioeconomic groups may reflect baseline differences in health behaviours, and that the interventions themselves may be effective across the socioeconomic spectrum. In their review of interventions targeted specifically at those disadvantaged by income, examining controlled studies (with or without random allocation) published between 1995 and 2006, they found 13 relevant studies with 17 available comparisons. Approximately half of interventions were reported as effective relative to controls, but no meta-analysis was performed to estimate an overall effect size. At present, there is a lack of evidence on the effectiveness of interventions specifically targeting health behaviour change in low-income individuals. ${ }^{24} 25$

The aim of the current systematic review is to build on Michie et $a l \mathrm{~s}^{23}$ work by (A) providing an updated review including studies published since 2006, (B) including only randomised controlled trials (RCTs) and (C) applying meta-analysis to estimate intervention effect sizes. We investigated whether studies of interventions targeted at participants from low-income groups are effective in changing diet, physical activity or smoking behaviour.

\section{METHODS}

\section{Eligibility criteria}

A protocol for this review is not publicly available; however, this article does reflect the relevant components of the PRISMA checklist for the reporting of systematic reviews. The article was submitted with a copy of the checklist confirming this.

Studies included in this review had to meet the following inclusion criteria:

- Population: Adults aged 18 years and over, of low income and from the general population. Studies were considered to target a low-income group if they explicitly referred to their participants as 'low income'. General population was defined as not belonging to a specific clinical group, such as those with diabetes or cardiovascular disease. Pregnant and overweight individuals were not considered to belong to a clinical group and were therefore included.

- Interventions: Interventions targeting a change in smoking, eating and/or physical activity behaviours. Studies could target a single behaviour or multiple behaviours in any combination.

- Study design: Published RCTs and cluster RCTs (cRCTs). Control condition could be no intervention, a less intense intervention or an intervention with different content.

- Outcomes: Behavioural outcomes relevant to smoking cessation, healthy eating and physical activity with no restrictions on length of follow-up. Self-reported individual-level behaviour, more 'objective' measures of behaviour and measures of behavioural change were all included, as in Michie et al..$^{23}$ Studies were excluded if reported data were unsuitable for meta-analysis.

- Date: 1995-2014: Studies published from 1995 to 2006 were identified by screening Michie $e t a{ }^{23}$ the primary search included studies published between January 2006 and July 2014. We chose to focus on studies published within the previous two decades to ensure relevance to current financial, social, health and healthcare climates.

- Language: English language: in line with Michie et $a l \mathrm{~s}^{23}$ review.

\section{Search strategy}

We used studies from 1995 to 2006 which had been identified by Michie $e t a l \mathrm{~s}^{23}$ review rather than running the search again because the previous review's search criteria were similar but broader than our own and should therefore include all articles relevant to the current review. Specific search strategies were created (see online supplementary file 1) to search for studies published since Michie $e$ t $a l \mathrm{~s}^{23}$ review of 1995-2006 papers. We searched eight databases: MEDLINE, EMBASE, PsycINFO, ASSIA, CINAHL, Cochrane Controlled Trials, Cochrane 
Systematic Reviews and DARE Electronic Databases. Search strategies were based on Michie et $a t^{23}$ and included three components: low-income population terms (eg, low-income, poverty, social class or socioeconomic status), terms for the three targeted health behaviours (eg, physical activity, diet, smoking cessation, lifestyle, health behaviour or weight reduction) and intervention-relevant terms (eg, behaviour/behaviour change, health program, intervention, health promotion or program evaluation). The specific strategies were iteratively created and tailored to each database's reference terms with an experienced NHS Clinical Librarian (PM). One author (ERB) initially ran the final searches on 1 December 2011 (January 2006-December 2011) and updated the search using the same search terms in the same databases on 10 July 2014 (December 2011-July 2014). In addition to the primary search, we checked the bibliography of each included study.

\section{Study selection}

One author (ERB) used the current review's inclusion criteria to screen the full texts of the 13 studies published between 1995 and 2006 included in Michie et al. ${ }^{23}$ For the studies published from 2006 onwards ERB, NM and SUD initially screened titles and abstracts, and obtained potentially relevant studies for full-text screening. If no abstract was available the full text was scanned at this first screening stage. If no full text was retrieved, or screening information was missing, ERB contacted the corresponding study author requesting further information. NM and ERB double screened a random sample of $10 \%$ of titles and abstracts from the studies from 2006 onwards which they had not previously screened $(\mathrm{n}=257)$, agreement with the primary screener was $96 \%$. Later in the screening process, NM screened a random sample of $10 \%$ of full-text articles assessed $(n=12)$, agreement was $92 \%$. The small number of disagreements were resolved through discussion.

\section{Data collection process}

Data were extracted using a prespecified and piloted data extraction form based on Davidson $e t a l \mathrm{~s}^{26}$ criteria, including study design, target behaviour, participants, recruitment strategies, intervention content and outcome data. Risk of bias in individual studies was assessed based on standard criteria adapted from Avenell et $a l^{27}$ Where published online supplementary materials were available they were used to assist data extraction (these are referred to in online supplementary table S1), and if information was missing, the corresponding author was contacted. When interventions targeted more than one behaviour, then data were extracted for the different behaviours separately. ERB, SUD, NM and MJ jointly extracted the outcome data.

Data were extracted for all reported time points. The primary outcome was behaviour or behaviour change following the end of the intervention. For the dichotomous smoking outcomes proportions were extracted (eg, per cent of sample reporting smoking abstinence for the past 7 days). For continuous diet and physical activity outcomes means and SDs were extracted (eg, mean portions of fruit and vegetables consumed per week). Where there was a choice of outcome measures, the outcome chosen was the primary behavioural outcome measure specified by the authors, measured by the most objective means (eg, accelerometer data were preferred to self-reported minutes of physical activity) and adjusted for baseline differences if this had been seen as necessary by the authors.

\section{Synthesis of results}

Data from included studies were meta-analysed in RevMan (V.5.2) using random effect models. For outcomes where a reduction (eg, mean percentage calories in fat) signifies a change in a healthy direction, data were reverse-scored before being entered for meta-analysis. For continuous diet and physical activity outcomes, standardised mean differences (SMD) were calculated using Hedges' $g^{28}$ to express the difference between the means for the intervention and control groups in SD units. For dichotomous smoking outcomes, we calculated relative risk (RR) of smoking abstinence and applied the Cochran-Mantel-Haenszel test. ${ }^{29}$

Where studies had multiple comparisons (several intervention arms or reported outcomes for different behaviours) or were cRCTs, we adjusted participant numbers in line with Cochrane recommendations where possible. ${ }^{30}$ We conducted meta-analyses for the three behaviours separately at two time points: the most proximal time point postintervention and the longest follow-up time point where reported. A 95\% CI was used and $\mathrm{p}<0.05$ was taken as significant. We assessed variation in effect size between studies using the $\mathrm{I}^{2}$ statistic, with an $\mathrm{I}^{2}$ $>50 \%$ interpreted as indicating the presence of heterogeneity. ${ }^{27}$ Following Cochrane Handbook recommendations, ${ }^{30}$ we compared independent subgroups of studies differing for two clinically relevant characteristics: interventions targeting women only versus a mixed sex sample, and interventions targeting a single behaviour versus multiple behaviours. Publication bias was assessed by visually inspecting funnel plots.

\section{RESULTS}

\section{Study selection}

A flow diagram is presented in figure 1 . We identified 3939 references from the database search (including the updated search: numbers for this search are given in figure 1) along with the 13 studies identified in Michie et $a l \mathrm{~s}^{23}$ review. After removing 1383 duplicates and excluding 2439 references on the basis of title and abstract screening 130 full texts were screened, of which 120 full texts were successfully retrieved, as 8 articles had no full text and 2 were irretrievable. Full-text screening initially led to the inclusion of 32 studies. Three further studies were identified from title screening reference 
Figure 1 Study selection flow diagram (italics signify numbers from July 2014 updated search).

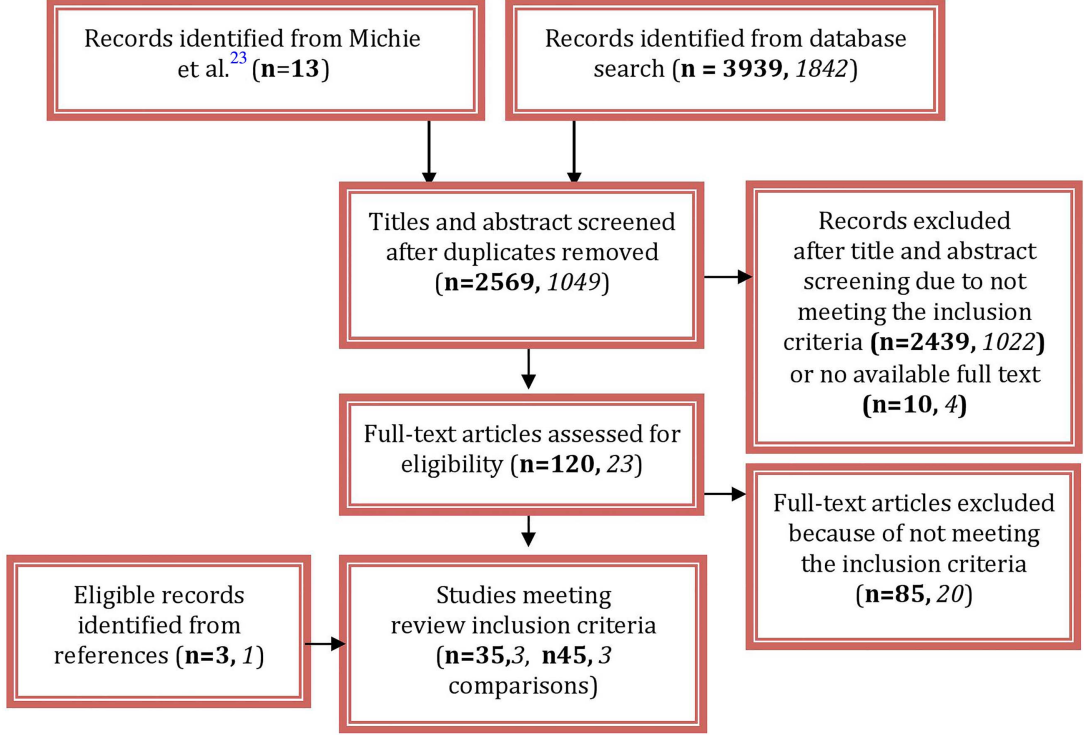

sections, so that 35 studies with 45 comparisons met inclusion criteria. ${ }^{25} 31-71$

\section{Study characteristics}

\section{Participant identification and recruitment}

Studies initially identified low-income participants through their place of residence (ie, living within an identified deprived area), by belonging to certain ethnic groups identified by the authors as suffering income inequality, being registered on a financial support programme, through belonging to a health clinic serving disadvantaged groups, by their employment (working in a manual workplace) or by an indicator of income (eg, quintile on the electoral role). Online supplementary table S1 describes how each study defined its study population as 'low income'. Twenty-three studies reported having measured participants' income as part of the study. Varying thresholds and income groupings were applied, but most commonly, incomes below US $\$ 15-$ US $\$ 20000$ (approximately $£ 8840-11800$ ) per year were considered 'low' and most studies reported that the majority of participants were in this category. Of the remaining 12 studies, 8 recruited participants from financial support programmes which required beneficiaries' earnings to be equivalent or near to official US poverty levels (which vary over time and depending on the individual's household size), 2 reported that the majority of participants held a manual, low wage occupation and the final 2 studies reported that participants' neighbourhoods had a high proportion of residents living in poverty.

Following initial identification, participants were recruited through face-to-face contact, via letter, telephone, via media advertisement or most commonly a mixture of methods. Face-to-face opportunities described were door-to-door neighbourhood recruitment, organisation of a community health fair, invitation at medical or social services appointments, or through presentations at schools or other community groups. Telephone calls were usually a follow-up method of contact. Media advertisements included posters in community venues, newspaper, radio and television advertisements. In the majority of cases, it was the study investigators who initiated these recruitment activities. Timeframe of recruitment varied from 1 day to over 2 years. Techniques used to engage low-income groups in participating were poorly specified: those most commonly reported were offers of material incentives (eg, vouchers for signing up), prompts and cues (eg, a fridge magnet with the study telephone number) or social support to facilitate participation (eg, advising about crèche facilities).

\section{Study design and participant characteristics}

The characteristics of the 35 included studies are summarised in online supplementary table S1. The majority $(\mathrm{k}=30)$ were conducted in the USA; the remaining studies were from the UK $(\mathrm{k}=3)$, Australia $(\mathrm{k}=1)$ and Chile $(\mathrm{k}=1)$. Twenty-eight studies were RCTs; seven were cRCTs. Studies took place in community $(\mathrm{k}=22)$, healthcare $(\mathrm{k}=12)$ or workplace $(\mathrm{k}=1)$ settings. Seven studies tested a dietary intervention, 7 studies tested a physical activity intervention, 15 studies tested a smoking intervention, and the remaining 6 tested interventions for multiple behaviours (5 tested diet and physical activity interventions, 1 tested diet and smoking interventions). Three studies had multiple intervention arms for one behaviour. In total, this yielded 16 interventions for the dietary meta-analysis, 12 interventions for physical activity meta-analysis and 17 for smoking meta-analysis. Each study randomised between 27 and 2549 participants, yielding a total of exactly 17000 participants across the 35 studies. Of the 34 studies specifying participants' sex, 19 targeted women exclusively and no study sampled only men. Women formed $72.4 \%$ of all participants. Mean average age of participants was 38.6, this ranged from 22.0 to 66.2 across study subgroups. 
Intervention content

The content of interventions varied from provision of tailored self-help materials, to individual counselling or group programmes, but was often complex and poorly described (see online supplementary table S1). Control groups in the intervention tended to receive usual care, a less intense version of the intervention or an inactive version (eg, non-tailored materials). Intervention duration varied from a single episode to 2 years; the mode duration was 3 months. The intervention facilitator was described in 18 studies. In 13 studies this was either a routine healthcare provider such as a nurse or general medical practitioner, or a 'non-routine' healthcare provider such as a psychologist, dietician or smoking counsellor. Of the remaining five studies, the facilitator was a peer educator in three studies and a study administrator in two.

\section{Intervention outcomes}

Twenty-one studies assessed the behavioural outcome using self-report; 14 studies included an objective measure relating to behaviour such as biochemically confirmed smoking cessation. For dietary interventions, the primary outcome was fruit and vegetables consumed, grams of fat, dietary risk assessment score (which estimates saturated fat and cholesterol intake) or calories from fat consumed per day. For physical activity, studies reported a wider range of outcomes including mean number of minutes or hours of moderate physical activity per week, metres walked in $6 \mathrm{~min}$, or metabolic equivalent minutes of activity per week. Smoking studies reported the number of participants who were abstinent from smoking, such as for the past 7 days, postpartum or for the previous 6 months. Studies differed in the delay between end of the intervention and most proximal assessment: this ranged from a few hours up to 8 months. Fourteen studies included follow-up data beyond the end of intervention time point. Overall $19.8 \%$ participants did not complete final assessments.

\section{Risk of bias within studies}

Online supplementary table S2 details the risk of bias assessment of the included studies. Risk of bias was variable. The majority of studies did not describe random allocation concealment procedures, provided numbers but not reasons for dropouts, did not mention blinding of any party and stated having used intention-to-treat analyses. There is therefore some risk of bias particularly during randomisation and surrounding blinding.

\section{Quantitative data synthesis: effectiveness of interventions \\ Diet}

Study outcomes are included in online supplementary table S3. The 16 dietary interventions were found to have an SMD of $0.22\left(95 \%\right.$ CI 0.14 to $0.29, \mathrm{I}^{2}=48 \%$; figure 2). Eight dietary interventions provided longer term follow-up data, for 6-12 months postbaseline with combined SMD of $0.16\left(95 \%\right.$ CI 0.08 to $\left.0.25, \mathrm{I}^{2}=41 \%\right)$.

\section{Physical activity}

Twelve physical activity interventions yielded an SMD of 0.21 (95\% CI 0.06 to $0.36, \mathrm{I}^{2}=76 \%$; figure 3 ). Three interventions provided longer term follow-up data 6-8 months postbaseline with a combined SMD of 0.17 $\left(95 \%\right.$ CI -0.02 to $\left.0.37, \mathrm{I}^{2}=0 \%\right)$.

Subgroup analyses for heterogeneity suggested SMDs were not different $(p=0.48)$ in four interventions targeting women only (SMD $0.14,95 \%$ CI 0.00 to 0.27 , $\mathrm{I}^{2}=0 \%$ ) compared with eight with a mixed sex sample (SMD 0.24, 95\% CI -0.02 to $0.49, \mathrm{I}^{2}=90 \%$ ). Effects were larger $(\mathrm{p}<0.001)$ in seven interventions targeting physical activity only (SMD $0.32,95 \%$ CI 0.18 to 0.45 , $\mathrm{I}^{2}=32 \%$ ) than five interventions targeting multiple behaviours including physical activity (SMD 0.00, 95\% CI -0.07 to $0.08, \mathrm{I}^{2}=0 \%$ ).

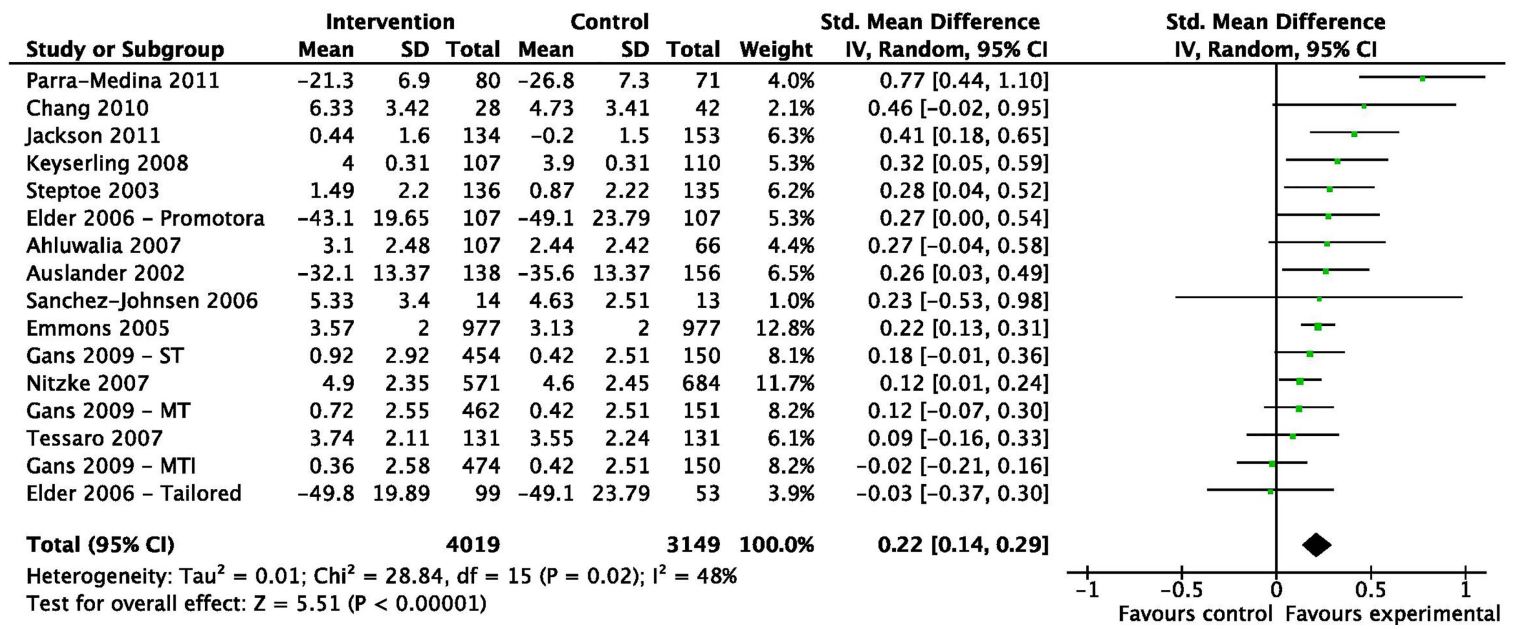

Figure 2 Standardised mean differences immediately postintervention for studies focusing on dietary change (ordered by effect size). 


\begin{tabular}{|c|c|c|c|c|c|c|c|c|c|c|c|}
\hline \multirow[b]{2}{*}{ Study or Subgroup } & \multicolumn{2}{|c|}{ Intervention } & \multicolumn{4}{|c|}{ Control } & \multicolumn{2}{|c|}{ Std. Mean Difference } & \multirow{2}{*}{\multicolumn{2}{|c|}{$\begin{array}{l}\text { Std. Mean Difference } \\
\text { IV, Random, } 95 \% \mathrm{CI}\end{array}$}} & \\
\hline & Mean & SD & Total & Mean & SD & Total & Weight & IV, Random, $95 \% \mathrm{CI}$ & & & \\
\hline Olvera 2010 & 2.1 & 1.6 & 18 & 1.2 & 0.9 & 17 & $3.6 \%$ & $0.67[-0.01,1.36]$ & & & \\
\hline Marcus 2013 & 73.36 & 89.73 & 132 & 32.98 & 82.82 & 134 & $10.3 \%$ & $0.47[0.22,0.71]$ & & $\longrightarrow$ & \\
\hline Dangour 2011 & 466.5 & 86.7 & 661 & 432.8 & 77.8 & 576 & $13.1 \%$ & $0.41[0.29,0.52]$ & & $=$ & \\
\hline Sanchez-Johnsen 2006 & 3.66 & 1.78 & 14 & 2.98 & 2.48 & 13 & $3.1 \%$ & $0.31[-0.45,1.07]$ & & & \\
\hline Pekmezi 2009 & 147.27 & 241.55 & 48 & 96.79 & 118.49 & 45 & $7.0 \%$ & $0.26[-0.15,0.67]$ & & & \\
\hline Chang 2010 & 41.09 & 29.87 & 28 & 33.51 & 29.34 & 42 & $5.8 \%$ & $0.25[-0.23,0.73]$ & & & \\
\hline Whitehead 2007 & $2,511.76$ & 25.89 & 103 & $2,506.72$ & 26.89 & 103 & $9.7 \%$ & $0.19[-0.08,0.46]$ & & - & \\
\hline Armitage 2010 & $1,080.62$ & $1,317.7$ & 32 & 868.33 & $1,659.01$ & 36 & $5.9 \%$ & $0.14[-0.34,0.62]$ & & & \\
\hline Jackson 2011 & 28 & 145 & 134 & 14 & 135 & 153 & $10.6 \%$ & $0.10[-0.13,0.33]$ & & - & \\
\hline Keyserling 2008 & 12.2 & 10.49 & 91 & 11.7 & 9.9 & 82 & $9.1 \%$ & $0.05[-0.25,0.35]$ & & - & \\
\hline Dutton 2007 & 0.7475 & 7.5845 & 69 & 0.5897 & 10.9895 & 70 & $8.4 \%$ & $0.02[-0.32,0.35]$ & & & \\
\hline Emmons 2005 & 4.77 & 5.31 & 977 & 4.91 & 5 & 977 & $13.4 \%$ & $-0.03[-0.12,0.06]$ & & & \\
\hline Total $(95 \% \mathrm{Cl})$ & & & 2307 & & & 2248 & $100.0 \%$ & $0.21[0.06,0.36]$ & & & \\
\hline $\begin{array}{l}\text { Heterogeneity: } \operatorname{Tau}^{2}=0 \text {. } \\
\text { Test for overall effect: } Z\end{array}$ & $\begin{array}{l}\text { 4; } \mathrm{Chi}^{2}= \\
=2.68(\mathrm{P}=\end{array}$ & $\begin{array}{l}.88, \mathrm{df} \\
.007)\end{array}$ & $=11(\mathrm{P}$ & $<0.00001$ & 1); $1^{2}=76 \%$ & & & & $\begin{array}{cc} & + \\
-1 & 0 \\
\text { perimental] }\end{array}$ & Favours [c & trol] \\
\hline
\end{tabular}

Figure 3 Standardised mean differences immediately postintervention for studies focusing on physical activity change (ordered by effect size).

\section{Smoking}

Seventeen smoking interventions were found to have a RR of smoking abstinence of 1.59 (95\% CI 1.34 to 1.89 , $\mathrm{I}^{2}=40 \%$; figure 4). Ten interventions provided longer term follow-up data for 3-12 months postbaseline. Positive intervention effects were not maintained; RR of smoking abstinence was 1.11 (95\% CI 0.93 to 1.34, $\left.\mathrm{I}^{2}=15 \%\right)$.

\section{Publication bias}

Visual inspection of funnel plots showed little evidence of publication bias.

\section{DISCUSSION}

\section{Summary of evidence}

We systematically reviewed the effectiveness of interventions targeted at changing the diet, physical activity or smoking of low-income groups. The review updates and extends a previous narrative review $^{23}$ by including recently published studies; incorporating RCTs only and applying meta-analysis to examine intervention effect.

We identified 35 studies containing 45 dietary, physical activity and smoking interventions. ${ }^{25} 31-71$ Studies used a wide range of methods to identify and engage lowincome participants. Most studies were conducted in the USA, contained mostly women and were often delivered by a healthcare professional. The quality of studies was variable with some risk of bias identified.

Our meta-analysis estimated a postintervention SMD of 0.22 for diet, 0.21 for physical activity interventions and a RR of smoking abstinence of 1.59 for smoking interventions. This means that the interventions had small positive effects on behaviour relative to controls. ${ }^{72}$ For studies reporting follow-up data, the small positive effects were maintained for diet (SMD 0.16) but not physical activity (SMD 0.17) or smoking cessation (RR 1.11). However long-term effects are based on a small subset of studies. Our exploration of the variation between physical activity interventions suggested that studies which focused on a single behaviour were more effective.

\section{Implications of findings}

We found small intervention effects on the behaviour of low-income groups compared with controls. For healthy eating, this was equivalent to intervention groups eating just under half a portion of fruit and vegetables more

\begin{tabular}{|c|c|c|c|c|c|c|c|c|}
\hline Study or Subgroup & \multicolumn{2}{|c|}{ Intervention } & \multicolumn{2}{|c|}{ Control } & Weight & $\begin{array}{c}\text { Risk Ratio } \\
\text { M-H, Random, } 95 \% \mathrm{Cl}\end{array}$ & \multicolumn{2}{|c|}{$\begin{array}{c}\text { Risk Ratio } \\
\text { M-H, Random, } 95 \% \mathrm{Cl}\end{array}$} \\
\hline Andrews 2007 & 14 & 51 & 3 & 52 & $1.9 \%$ & $4.76[1.45,15.57]$ & & \\
\hline Volpp 2006 & 15 & 92 & 4 & 87 & $2.3 \%$ & $3.55[1.22,10.27]$ & & \\
\hline Skyes 2001 & 21 & 122 & 6 & 107 & $3.3 \%$ & $3.07[1.29,7.32]$ & & \\
\hline Dornelas 2006 & 15 & 53 & 5 & 52 & $2.9 \%$ & $2.94[1.15,7.51]$ & & \\
\hline Liles 2009 & 15 & 76 & 5 & 74 & $2.8 \%$ & $2.92[1.12,7.63]$ & & \\
\hline Gordon 2010 & 28 & 530 & 8 & 439 & $3.9 \%$ & $2.90[1.33,6.30]$ & & \\
\hline Wu 2009 & 40 & 60 & 20 & 62 & $9.3 \%$ & $2.07[1.38,3.09]$ & & $\longrightarrow$ \\
\hline Fang 2006 & 15 & 34 & 8 & 32 & $4.5 \%$ & $1.76[0.87,3.59]$ & & \\
\hline Miller 2009 & 397 & 1000 & 97 & 377 & $15.3 \%$ & $1.54[1.28,1.86]$ & & - \\
\hline Solomon 2000 & 44 & 106 & 30 & 108 & $9.9 \%$ & $1.49[1.02,2.18]$ & & $=$ \\
\hline Reitzel 2010 & 31 & 136 & 19 & 115 & $7.1 \%$ & $1.38[0.82,2.31]$ & & $=$ \\
\hline Solomon 2005 & 82 & 171 & 58 & 159 & $13.2 \%$ & $1.31[1.02,1.70]$ & & - \\
\hline Bullock 2009 - SS v C & 29 & 132 & 22 & 128 & $7.3 \%$ & $1.28[0.78,2.10]$ & & - \\
\hline Froelicher 2010 & 3 & 22 & 3 & 26 & $1.3 \%$ & $1.18[0.26,5.28]$ & & \\
\hline Okuyemi 2013 & 20 & 216 & 19 & 214 & $5.8 \%$ & $1.04[0.57,1.90]$ & & - \\
\hline Bullock - SS+B vs. B & 22 & 129 & 27 & 141 & $7.1 \%$ & $0.89[0.53,1.48]$ & & - \\
\hline Ahluwalia 2007 & 4 & 57 & 9 & 93 & $2.1 \%$ & $0.73[0.23,2.25]$ & & \\
\hline Total $(95 \% \mathrm{Cl})$ & & 2987 & & 2266 & $100.0 \%$ & $1.59[1.34,1.89]$ & & $>$ \\
\hline Total events & 795 & & 343 & & & & & \\
\hline $\begin{array}{l}\text { Heterogeneity: } \mathrm{Tau}^{2}= \\
\text { Test for overall effect: }\end{array}$ & $\begin{array}{l}.04 ; \mathrm{Chi}^{2} \\
=5.25\end{array}$ & $=26.77$ & $\begin{array}{l}7, d f=1 \\
0001)\end{array}$ & $6(P=$ & $0.04) ; 1^{2}=$ & $=40 \%$ & 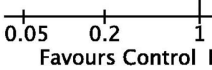 & Favours In \\
\hline
\end{tabular}

Figure 4 Relative risk of smoking abstinence immediately postintervention for studies focusing on smoking interventions (ordered by effect size). 
than controls each day. Similar reviews not targeting lowincome participants tend to report larger effects: four such reviews targeting adults in the general population $^{73-75}$ or obese adults with additional risk factors ${ }^{76}$ reported larger effects for diet (SMD 0.31), ${ }^{75}$ physical activity (SMD 0.28-0.32) 737576 and smoking (RR 2.17) interventions. ${ }^{74}$ Although true comparison is not possible unless the same interventions were compared in different population groups, this does suggest that interventions may be less effective for low-income populations. If other population groups benefit more from current interventions, even than those specifically targeted at low-income groups, then we can expect an overall gradual widening of health inequalities, as has been reported. ${ }^{2}$ Clearly research with more effective interventions is needed, including RCTs conducted in the UK, to increase our understanding of 'what works' for low-income groups.

Our analysis of the variation in physical activity studies showed a trend towards studies being more effective if they target a single behaviour than two behaviours. In addition, only one smoking study targeted both smoking and $\operatorname{diet}^{3132}$ and this was the study with the lowest overall effect size. This resonates with the argument that human self-regulation draws on limited resources ${ }^{77} 78$ which may be best applied to one behaviour change target at a time. In contrast, physical activity studies including women only did not seem to vary widely in effectiveness from those with a mixed sex sample. Nevertheless there may be other unexplored sources of heterogeneity including other aspects of the delivery of interventions, such as those in the TIDIER checklist ${ }^{79}$ or use of techniques from the recently published Behaviour Change Technique taxonomy v1. ${ }^{80}$

\section{Limitations}

This study was a systematic but not exhaustive review, for instance not including informally published reports or 'grey literature', which tend not to be indexed within conventional databases. It limited its scope to RCTs and cluster RCTs to gather the highest quality evidence available, but some authors argue that reviewers should include less well-controlled studies because they often have enhanced external validity. ${ }^{81}$ In common with similar reviews ${ }^{82}$ methodological quality of studies was variable: for example, few studies blinded participants, facilitators or outcome assessors to treatment group. However, blinding of treatment condition in behavioural interventions is notoriously difficult: this is a criticism common to many similar reviews. ${ }^{83}$

Definitions of and thresholds for 'low income' varied somewhat between studies, reflecting the fact that there is no one agreed-on 'cut-off' for low income. We specified that the term 'low income' had to be used to refer to participants for studies to be included, since this is a relevant deprivation indicator in our financial and social context, perhaps more so than others such as education level. However, relevant papers not using this term may have been missed, particularly studies from some settings (eg, perhaps a church setting) where income may have been less likely to have been measured than others (eg, the workplace). Nevertheless, our review did identify studies using a wide range of concepts to target low socioeconomic status, such as area of residence, belonging to certain ethnic groups, belonging to a health clinic serving disadvantaged groups, as well as concepts directly linked to low income, such as indicator of income. Therefore, using the term 'low income' allowed us to implement a clear, objective and replicable criterion for including studies in the review, while also allowing us to capture studies considering low socioeconomic status in a variety of ways.

Additionally, the majority of studies were conducted in the USA, limiting generalisability to the UK context, although effect sizes for the UK studies fell within the typical range. Interventions were generally poorly specified. Categorisation or coding of control group content was not possible, even though studies show that this may vary substantially and influence intervention outcomes. ${ }^{84}$ Our review is also limited in scope to studies written in the English language. A final caveat for our findings is that while we excluded a study where the authors advised us that the data were zero-inflated, ${ }^{85}$ this may have been true of other studies.

\section{CONCLUSIONS}

This systematic review with meta-analysis of randomised controlled interventions to improve the diet, physical activity or smoking behaviour of low-income groups found small positive effects of interventions on behaviour compared with controls, which persisted over time only for diet. Despite research highlighting the urgent need for effective behaviour change support for people from low-income groups to assist in reducing health inequalities, ${ }^{10-12}$ this review suggests that our current interventions for low-income groups are positive, but small, risking 'intervention-generated inequalities'. ${ }^{22}$ Policy makers and practitioners alike should seek improved interventions for disadvantaged populations to change health behaviours in the most vulnerable people and reduce health inequalities.

Acknowledgements The authors are grateful for the assistance of Mr Paul Manson, NHS Grampian Clinical Librarian, in the design of search strategies. They would also like to sincerely thank Professor Susan Michie, University College London, Dr Linda Leighton-Beck, NHS Grampian Keep Well Programme Director and Mrs Dorothy Ross-Archer, NHS Grampian Keep Well Programme Manager. Finally, they are also very grateful to the study authors who kindly provided additional data or advice for the review.

Contributors ERB and MJ had the original idea for the paper and designed the review method and analyses. ERB, SUD, NM and MJ participated in study selection and data extraction. ERB and SUD conducted statistical analysis. ERB, SUD, NM and MJ participated in writing the manuscript. ERB is the guarantor for the study.

Funding This research received no specific grant from any funding agency in the public, commercial or not-for-profit sectors. 
Competing interests ERB is an employee of NHS Grampian. SUD is an employee of University of Stirling. NM is a PhD student at the University of Aberdeen. MJ is an emeritus professor at of University of Aberdeen.

Provenance and peer review Not commissioned; externally peer reviewed.

Data sharing statement No additional data are available.

Open Access This is an Open Access article distributed in accordance with the Creative Commons Attribution Non Commercial (CC BY-NC 4.0) license, which permits others to distribute, remix, adapt, build upon this work noncommercially, and license their derivative works on different terms, provided the original work is properly cited and the use is non-commercial. See: http:// creativecommons.org/licenses/by-nc/4.0/

\section{REFERENCES}

1. Office for National Statistics. Inequality in Disability-free life expectancy by area deprivation: England, 2002-05 and 2006-09. 2012. http://www.ons.gov.uk/ons/dcp171778_265133.pdf (accessed 14 Feb 2014)

2. Marmot M, Atkinson T, Bell J, et al. Fair society, healthy lives: the Marmot Review: strategic review of health inequalities in England post-2010. London: The Marmot Review, 2010.

3. Adler N, Boyce W, Chesney M, et al. Socioeconomic inequalities in health: no easy solution. J Am Med Assoc 1993;269:3140-5.

4. Department of Health. Choosing health. London: Stationery Office, 2004. (White paper)

5. Scottish Government. Equally well: report of the ministerial task force on health inequalities. Edinburgh: The Stationery Office, 2008.

6. Mokdad A, Marks J, Stroup D, et al. Actual causes of death in the United States, 2000. JAMA 2004;291:1238-45.

7. World Health Organisation. The world health report 2002. Geneva: World Health Organisation, 2002.

8. Stamatakis E. Obesity, eating and physical activity. In: Bajekal M, Osborne V, Yar M, Meltzer M. eds. Focus on health London. Office for National Statistics/Palgrave Macmillan, 2006:47-61.

9. Drewnowski A, Specter S. Poverty and obesity: the role of energy density and energy costs. Am J Clin Nutr 2004;79:6-16.

10. Whitley E, Batty GD, Hunt K, et al. The role of health behaviours across the life course in the socioeconomic patterning of all-cause mortality: the west of Scotland twenty-07 prospective cohort study. Ann Behav Med 2014;47:148-57.

11. Hart C, Gruer L, Watt G. Cause specific mortality, social position, and obesity among women who had never smoked: 28 year cohort study. BMJ 2011;342:d3785

12. Gruer L, Hart CL, Gordon DS, et al. Effect of tobacco smoking on survival of men and women by social position: a 28 year cohort study. BMJ 2009;338:480.

13. Doll R, Peto R, Boreham J, et al. Mortality in relation to smoking: 50 years' observations on male British doctors. BMJ 2004;328:1519.

14. House of lords: Science and technology select sub-committee. 2nd Report of session 2010-12: behaviour change. London: HMSO, 2011.

15. Wanless D. Securing good health for the whole population: final report. London: Stationery Office, 2004.

16. Anderson A. Dietary interventions in low-income women: issues for UK Policy. Nutr Bull 2007;32:15-20.

17. Marcus $B$, Williams $D$, Dubbert $P$, et al. Physical activity intervention studies: what we know and what we need to know. A scientific statement from the American Heart Association council on nutrition, physical activity, and metabolism (subcommittee on physical activity); council on cardiovascular diseases in the young; and the interdisciplinary working group on quality of care and outcomes research. Circulation 2006;114:2739-52.

18. Shah LM, Arora V, King A, et al. The presence of tobacco cessation programs is not sufficient for low-income hospitalized smokers. Arch Intern Med 2009;169:902-3.

19. Hiscock R, Judge K, Bauld L. Social inequalities in quitting smoking: what factors mediate the relationship between socioeconomic position and smoking cessation? J Public Health 2011;33:39-47.

20. Niederdeppe J, Fiore MC, Baker TB, et al. Smoking-cessation media campaigns and their effectiveness among socioeconomically advantaged and disadvantaged populations. Am J Public Health 2008;98:916-24.

21. Chesterman J, Judge K, Bauld L, et al. How effective are the English smoking treatment services in reaching disadvantaged smokers? Addiction 2005;100:36-45.
22. White M, Adams J, Heywood P. How and why do interventions that increase health overall widen inequalities within populations? In: Barbones S. ed. Health, inequality and public health. Bristol: Policy Press, 2009:65-81.

23. Michie S, Jochelson K, Markham WA, et al. Low-income groups and behaviour change interventions: a review of intervention content, effectiveness and theoretical frameworks. J Epidemiol Community Health 2009;63:610-22.

24. National Institute of Health and Clinical Excellence (NICE). Behaviour change at population, community and individual levels (Public Health Guidance 6). London: NICE, 2007.

25. Armitage CJ, Arden MA. A volitional help sheet to increase physical activity in people with low socioeconomic status: a randomised exploratory trial. Psychol Health 2010;25:1129-45.

26. Davidson $\mathrm{K}$, Goldstein M, Kaplan $\mathrm{R}$, et al. Evidence-based behavioural medicine: what is it and how do we achieve it? Ann Behav Med 2003;26:161-71.

27. Avenell A, Broom J, Brown T, et al. Systematic review of the long-term effects and economic consequences of treatments for obesity and implications for health improvement. Health Technol Assess 2004;8:1-182.

28. Hedges L. Distribution theory for Glass's estimator of effect size and related estimators. J Educ Behav Stat 1981;6:107-28.

29. Mantel N, Haenszel W. Statistical aspects of the analysis of data from retrospective studies of disease. J Natl Cancer Inst 1959;22:719-48.

30. Higgins J, Green S. Cochrane handbook for systematic reviews of interventions version 5.1.0 [updated March 2011]. The Cochrane Collaboration, 2011.

31. Ahluwalia JS, Nollen N, Kaur H, et al. Pathways to health: cluster-randomized trial to increase fruit and vegetable consumption among smokers in public housing. Health Psychol 2007;26:214-21.

32. Okuyemi KS, James AS, Mayo MS, et al. Pathways to health: a cluster randomized trial of nicotine gum and motivational interviewing for smoking cessation in low-income housing. Health Educ Behav 2007;34:43-54.

33. Auslander W, Haire-Joshu D, Houston C, et al. A controlled evaluation of staging dietary patterns to reduce the risk of diabetes in African-American women. Diabetes Care 2002;25:909-14.

34. Chang MW, Nitzke S, Brown R. Design and outcomes of a mothers in motion behavioral intervention pilot study. J Nutr Educ Behav 2010;42(3 Suppl):S11-21.

35. Chang MW, Brown R, Nitzke S. Participant recruitment and retention in a pilot program to prevent weight gain in low-income overweight and obese mothers. BMC Public Health 2009;9:424

36. Elder J, Ayala G, Campbell N, et al. Long-term effects of a communication intervention for Spanish-dominant Latinas. Am J Prev Med 2006;31:159-66.

37. Emmons K, Stoddard A, Flotcher R, et al. Cancer prevention among working class, multiethnic adults: results of the healthy directions-health centers study. Am J Public Health 2005;95:1200-5.

38. Gans KM, Risica PM, Strolla LO, et al. Effectiveness of different methods for delivering tailored nutrition education to low-income, ethnically diverse adults. Int J Behav Nutr Phys Act 2009;6:24.

39. Jackson RA, Stotland NE, Caughey AB, et al. Improving diet and exercise in pregnancy with Video Doctor counseling: a randomized trial. Patient Educ Couns 2011;83:203-9.

40. Keyserling TC, Samuel Hodge CD, Jilcott SB, et al. Randomized trial of a clinic-based, community-supported, lifestyle intervention to improve physical activity and diet: the North Carolina enhanced WISEWOMAN project. Prev Med 2008;46:499-510.

41. Jilcott SB, Keyserling TC, Samuel-Hodge CD, et al. Linking clinical care to community resources for cardiovascular disease prevention: the North Carolina Enhanced WISEWOMAN project. $J$ Womens Health 2006;15:569-83.

42. Nitzke S, Kritsch K, Boeckner L, et al. A stage-tailored multi-modal intervention increases fruit and vegetable intakes of low-income young adults. Am J Health Promot 2007;22:6-14.

43. Nitzke S, Kritsch K, Lohse B, et al. Extension and research professionals join forces to address a critical nutrition issue. JOE 2004;42.

44. Parra-Medina D, Wilcox S, Salinas J, et al. Results of the heart healthy and ethnically relevant lifestyle trial: a cardiovascular risk reduction intervention for African American women attending community health centers. Am J Public Health

2011:101:1914-21.

45. Sanchez-Johnsen LA, Stolley MR, Fitzgibbon ML. Diet, physical activity, and breast health intervention for Latina women. Hispanic Health Care Int 2006;4:101-10.

46. Steptoe A, Perkins-Porras L, McKay C, et al. Behavioural counselling to increase consumption of fruit and vegetables in low-income adults: randomised trial. BMJ 2003;326:855. 
47. Tessaro I, Rye S, Parker L, et al. Effectiveness of a nutrition intervention with rural low-income women. Am J Health Behav 2007;31:35-43

48. Dangour AD, Albala C, Allen $\mathrm{E}$, et al. Effect of a nutrition supplement and physical activity program on pneumonia and walking capacity in Chilean older people: a factorial cluster randomized trial. PLoS Med 2011;8:e1001023.

49. Dangour A, Albala C, Aedo C, et al. A factorial-design cluster randomised controlled trial investigating the cost-effectiveness of a nutrition supplement and an exercise programme on pneumonia incidence, walking capacity, and body mass index in older people living in Santiago, Chile: the CENEX study protocol. Nutr $J$ 2007;6:14.

50. Dutton GR, Davis Martin P, Welsch MA, et al. Promoting physical activity for low-income minority women in primary care. Am J Health Behav 2007;31:622-31.

51. Marcus BH, Dunsiger SI, Pekmezi DW, et al. The seamos saludables study: a randomized controlled physical activity trial of Latinas. Am J Prev Med 2013;45:598-605.

52. Olvera NN, Bush JA, Sharma SV, et al. BOUNCE: a communitybased mother-daughter healthy lifestyle intervention for low-income Latino families. Obesity 2010;18(Suppl 1):S102-4.

53. Olvera NN, Knox B, Scherer R, et al. A healthy lifestyle program for Latino daughters and mothers: the BOUNCE overview and process evaluation. Am J Health Ed 2008;39:283-95.

54. Pekmezi DW, Neighbors CJ, Lee CS, et al. A culturally adapted physical activity intervention for Latinas: a randomized controlled trial. Am J Prev Med 2009;37:495-500.

55. Whitehead D, Bodenlos JS, Cowles ML, et al. A stage-targeted physical activity intervention among a predominantly African-American low-income primary care population. Am J Health Promot 2007;21:160-3.

56. Andrews JO, Felton G, Wewers ME, et al. The effect of a multi-component smoking cessation intervention in African-American women residing in public housing. Res Nurs Health 2007;30:45-60.

57. Andrews JO, Felton G, Wewers ME, et al. Sister to sister: a pilot study to assist African American women in subsidized housing to quit smoking. South Online J Nurs Res 2005;6:2-23.

58. Bullock L, Everett KD, Mullen PD, et al. Baby BEEP: a randomized controlled trial of nurses' individualized social support for poor rural pregnant smokers. Matern Child Health J 2009;13:395-406.

59. Dornelas EA, Magnavita J, Beazoglou T, et al. Efficacy and cost-effectiveness of a clinic-based counseling intervention tested in an ethnically diverse sample of pregnant smokers. Patient Educ Couns 2006;64:342-9.

60. Fang $\mathrm{CY}, \mathrm{Ma} \mathrm{GX}$, Miller SM, et al. A brief smoking cessation intervention for Chinese and Korean American smokers. Prev Med 2006;43:321-4.

61. Froelicher ES, Doolan D, Yerger VB, et al. Combining community participatory research with a randomized clinical trial: the protecting the hood against tobacco (PHAT) smoking cessation study. Heart Lung 2010;39:50-63.

62. Gordon JS, Andrews JA, Albert DA, et al. Tobacco cessation via public dental clinics: results of a randomized trial. Am J Public Health 2010;100:1307-12.

63. Liles S, Hovell MF, Matt GE, et al. Parent quit attempts after counseling to reduce children's secondhand smoke exposure and promote cessation: main and moderating relationships. Nicotine Tob Res 2009;11:1395-406.

64. Miller CL, Sedivy V. Using a quitline plus low-cost nicotine replacement therapy to help disadvantaged smokers to quit. Tob Control 2009;18:144-9.

65. Okuyemi KS, Goldade K, Whembolua GL, et al. Motivational interviewing to enhance nicotine patch treatment for smoking cessation among homeless smokers: a randomized controlled trial. Addiction 2013;108:1136-44.

66. Reitzel LR, Vidrine JI, Businelle MS, et al. Preventing postpartum smoking relapse among diverse low-income women: a randomized clinical trial. Nicotine Tob Res 2010;12:326-35.

67. Solomon LJ, Scharoun GM, Flynn BS, et al. Free nicotine patches plus proactive telephone peer support to help low-income women stop smoking. Prev Med 2000;31:68-74.

68. Solomon LJ, Marcy TW, Howe KD, et al. Does extended proactive telephone support increase smoking cessation among low-income women using nicotine patches? Prev Med 2005;40:306-13.

69. Sykes CM, Marks DF. Effectiveness of a cognitive behaviour therapy self-help programme for smokers in London, UK. Health Promot Int 2001;16:255-60.

70. Volpp KG, Gurmankin Levy A, Asch DA, et al. A randomized controlled trial of financial incentives for smoking cessation. Cancer Epidemiol Biomarkers Prev 2006;15:12-18.

71. Wu D, Ma GX, Zhou K, et al. The effect of a culturally tailored smoking cessation for Chinese American smokers. Nicotine Tob Res 2009;11:1448-57.

72. Cohen J. A power primer. Psychol Bull 1992;112:155-9.

73. Foster $\mathrm{C}$, Hillsdon M, Throrogood M, et al. Interventions for promoting physical activity. Cochrane Database Syst Rev 2013; (1):14651858.

74. Lemmens V, Oenema A, Knut I, et al. Effectiveness of smoking cessation interventions among adults: a systematic review of reviews. Eur J Cancer Prev 2008;17:535-44.

75. Michie S, Abraham C, Whittington $\mathrm{C}$, et al. Effective techniques in healthy eating and physical activity interventions: a meta-regression. Health Psychol 2009;28:690-701.

76. Dombrowski S, Sniehotta F, Avenell A, et al. Identifying active ingredients in complex behavioural interventions for obese adults with obesity-related co-morbidities or additional risk factors for co-morbidities: a systematic review. Health Psychol Rev 2012;6:7-32.

77. Baumeister R, Bratslavsky E, Muraven M, et al. Ego depletion: is the active self a limited resource? J Pers Soc Psychol 1998; 74:1252-65.

78. Vohs K, Heatherton T. Self-regulatory failure: a resource-depletion approach. Psychol Sci 2000;11:249-54.

79. Hoffmann T, Glasziou P, Boutron I, et al. Better reporting of interventions: the Template for Intervention Description and Replication (TIDieR) checklist and guide. BMJ 2014;348:g1687.

80. Michie S, Richardson M, Johnston M, et al. The behavior change technique taxonomy (v1) of 93 hierarchically clustered techniques: building an international consensus for the reporting of behavior change interventions. Ann Behav Med 2013;46:81-95

81. Glasgow R, Green L, Klesges L, et al. External validity: we need to do more. Ann Behav Med 2006;31:105-8.

82. Agency for Healthcare Research and Quality. Efficacy of interventions to modify dietary behavior related to cancer risk. Evidence Report/Technology Assessment No. 25. Rockville: Agency for Healthcare Research and Quality, 2000.

83. Boutron I, Moher D, Altman D, et al. Extending the CONSORT statement to randomized trials of nonpharmacologic treatment: explanation and elaboration. Ann Intern Med 2008;148:295-309.

84. deBruin M, Viechtbauer W, Hospers HJ, et al. Standard care quality determines treatment outcomes in control groups of HAART-Adherence intervention studies: implications for the interpretation and comparison of intervention effects. Health Psychol 2009;28:668-74.

85. Hovell MF, Mulvihill M, Buono MJ, et al. Culturally tailored aerobic exercise intervention for low-income Latinas. Am J Health Promot 2008;22:155-63. 